\title{
MODERNIDAD Y ENTUSIASMO: A PROPÓSITO DE LA LECTURA FOUCAULTIANA DE KANT
}

\author{
Edgardo Castro \\ Universidad de San Martín (Argentina)
}

"Es necesario tratar de hacer la genealogía no tanto de la noción de modernidad, sino de la modernidad como cuestión". ${ }^{1}$

1. La modernidad y sus compuestos (premoderno, postmoderno, antimoderno) no se prestan fácilmente a la definición. ¿Cuál es el elemento que define la modernidad? ¿Cuándo comienza? ¿Filosóficamente con el cogito cartesiano, como piensa Hegel, ${ }^{2}$ o, como sostiene Foucault en Les Mots et les choses, ${ }^{3}$ recién con Kant? ¿Con la modernidad literaria, que Sartre sitúa alrededor de 1850, o con la modernidad en pintura? Y, en este último caso, ¿con el impresionismo entre 1870 y 1880 o con el cubismo de los primeros años del siglo XX? ${ }^{4}$

En cuanto al término, si bien en las lenguas modernas el substantivo "modernidad" aparece en el siglo XIX, sus orígenes se remontan a un neologismo latino que comienza a difundirse en los últimos años del siglo $\mathrm{V}$. El adjetivo modernus, en efecto, es utilizado por el papa Gelasio, ${ }^{5}$ que gobernó la Iglesia entre el 492 y 496. Ya en Gelasio nos encontramos con la característica polaridad entre lo antiguo y lo moderno que definirá gran parte de la historia de estos términos. En este caso, para distinguir las normativas de los padres de la Iglesia (los sucesores de los apóstoles hasta el Concilio de Calcedonia, del 451) de las de los últimos sínodos romanos. La distancia entre la antigüedad y los tiempos modernos es aquí de apenas unos 50 años.

En cuanto al substantivo modernitas, el primer testimonio se encuentra en Bertoldo de Reichenau (o Constantiensis). Otro autor de la época, Gautier Map, en De nugis curialium (1180-1192), hace un uso frecuente del término “modernitas" para referirse a los últimos cien años, a aquellos acontecimientos de los que todavía se tiene memoria. Y por esta misma

\footnotetext{
${ }^{1}$ M. Foucault. “Qu'est-ce que les Lumières?”, Dits et écrits. Vol. IV. Paris: Gallimad, 1994, p. 681.

${ }^{2}$ Cf. G. W. F. Hegel. Werke. Vorlesungen über der Geschichte der Philosophie. Vol. 20. Frankfurt: Suhrkamp, 1970, p. 119.

${ }^{3}$ Cf., por ejemplo, M. Foucault. Les Mots et les choses. Paris, 1966, pp. 16, 315, 328. Como veremos, la modernidad, para Foucault no es sólo el nombre de un período histórico cuyos inicios sitúa a veces a partir de Kant y otras, como en L'Hermenéutique du sujet, a partir de Descartes; sino también una actitud.

${ }^{4}$ Acerca de estas múltiples dataciones, cf. Henri Meschonnic. Modernité, Modernité, Paris: Gallimard, 1988, pp. 23-26.

5 "Quis aut leges principum, aut Patrum regulas, aut admonitiones modernas dicat debere contemni, nisi qui impunitum sibi tantum aestimet transire commissum" (Epistolae pontificicum. Gelasius rufino et aprili episcopis, en Migne, Patrologia latina, 59, 152C). Texto de atribución discutida.
} 
época, durante la Querella de las investiduras (1076-1122), el término es usado para referirse a una "edad intermedia" entre la Antigüedad y la de una necesaria reforma. ${ }^{6}$

Como nombre del período histórico que algunos, como Hegel, retrotraen hasta el siglo XVI, en el lenguaje historiográfico, el término recién se consolidó en los últimos años del siglo XIX. ${ }^{7}$ Su significación ha sido el producto de un proceso de lenta maduración, en el que una determinación temporal, moderno como actual, terminó convirtiéndose en la expresión cualitativa de una época: moderno como enfáticamente nuevo e, incluso, axiológicamente mejor.

2. Respecto de este valor axiológico de la categoría de modernidad, han sido emblemáticas las primeras líneas del famoso artículo de Kant, Was ist Auflelärung?: la ilustración es la salida del hombre de la minoría de edad. ${ }^{8}$ No es ciertamente una metáfora completamente inédita. Para citar sólo un ejemplo, que, como Kant, la emplea también en relación con las capacidades cognitivas del hombre; Pascal, en el prefacio al Traité du vide, sostiene que "la sucesión de los hombres, a través de los siglos, debe ser considerada como un único hombre que subsiste y aprende continuamente", "aquellos a quienes llamamos antiguos eran verdaderamente nuevos en todas las cosas y constituían propiamente la infancia de los hombres, $\mathrm{y}$, dado que nosotros hemos añadido a sus conocimientos la experiencia de los siglos que los siguieron, es en nosotros que se puede encontrar esta antigüedad que veneramos en los otros".?

Se trata, como vemos, de una misma imagen, en que la de la humanidad es considerada como un único individuo y, consecuentemente, su historia es interpretada como el desarrollo de la vida individual, marcado por los momentos de la infancia y la adultez. Pero las diferencias saltan a la vista. Para Pascal, en efecto, la madurez, que lo convierte a él y a sus contemporáneos en verdaderamente antiguos, es la época en la que, para expresarlo de algún modo, la novedad ya no es lo que era. Para Kant, en cambio, no es la experiencia de los siglos la que saca a los hombres de la infancia; sino una determinada disposición de la voluntad que constituye, en sí misma, una verdadera novedad.

Un cambio igualmente revelador afecta a ese otro concepto cuya suerte está históricamente ligada a la del concepto de modernidad: revolución. El título de la obra de

\footnotetext{
${ }^{6}$ Las referencias de la historia latina de los términos "modernus" y "modernitas" las hemos tomado de H. Jauss. Pour une esthétique de la réception. Paris, 1998, págs. 173-229 y W. Freund. Modernus und andere Zeitbegriffe des Mittelalters. Köhln-Graz: Böhlau, 1957.

${ }^{7}$ Cf. R. Koselleck. Vergangene Zukunft. Zur Semantike geschichtlicher Zeiten. Frankfurt: Suhrkamp, 1995, pp. 302 y ss.

${ }^{8}$ Cf. I. Kant. Was ist Aufklärung?, AK VIII, p. 35.

${ }^{9}$ B. Pascal. « Préface sur le Traité du vide », Oeuvres complètes. Paris: Hachette, 1963, pág. 232.
} 
Copérnico ha jugado, sin duda, un papel de primer orden en la circulación y uso que se ha hecho de este término. Basta recordar el prefacio a la segunda edición de la Kritik der reinen Vernunft, donde Kant concibe su empresa filosófica, precisamente, como una revolución copernicana. Y, sin embargo, el sentido del término "revolución" en la expresión "revolución copernicana" es el contrario del que posee en el título de la obra de Copérnico. En efecto, astronómicamente, cuando habla de revolutionibus orbium coelestium, Copérnico hace referencia a un movimiento circular en que se vuelve (re-volutio) al punto de partida. La expresión "revolución copernicana", por el contrario, sirve para hablar de un nuevo estado de las cosas. Del mismo modo, también en el vocabulario político, "revolución” deja de ser sinónimo de "restauración", como sucedía todavía en la época de Hobbes, y pasa a significar precisamente lo contrario. ${ }^{10}$

Como señala Hannah Arendt, la Antigüedad conocía los cambios políticos, las metabolaí de Platón o los ciclos de Polibio daban cuenta de ellos. Se pasaba de una forma política a otra, a través de sus degeneraciones: de la monarquía a la aristocracia, a través de la tiranía; de la aristocracia a la democracia, a través de la oligarquía; de la democracia nuevamente a la monarquía, a través de la anarquía. Pero ninguno de los conceptos con que los antiguos pensaron estos cambios es equivalente a nuestro concepto de revolución; en ese sucederse natural de las distintas formas políticas, no era posible hablar de novedad en sentido enfático. ${ }^{11}$

3. Tanto la modificación en el uso de la metáfora evolutiva de la humanidad como la nueva semántica del término "revolución", han sido posibles a partir de una concepción de la temporalidad histórica que rompe en varios puntos con la concepción cíclica de la Antigüedad clásica. Los supuestos constitutivos de esta nueva concepción de la temporalidad han dado lugar a toda una discusión, cargada de consecuencias y todavía abierta, cuyo eje es la categoría de secularización.

El término, como sabemos, proviene del latín saeculum (siglo), utilizado por la Vulgata para traducir el griego aión. "Siglo" (saeculum) no expresa aquí el período de cien años, sino una época y, en particular, el presente. Su significado se superpone, al menos en parte, con la semántica del adjetivo modernus.

${ }^{10}$ Cf. H. Arendt. On Revolution. London: Penguin Books, 1990, pp. 22 y ss. Al respecto, Koselleck hace referencia al artículo de B. Hauréau del Dictionnaire Politique, Encyclopédie du Langage et de la science Politique, donde el autor llama la atención precisamente sobre el haber olvidado que el término "revolución" expresaba originariamente un regreso (cf. Vergangene Zukunft. Zur Semantik geschichtlicher Zeiten. Frankfurt: Suhrkamp, 1995, p. 69-70).

${ }^{11}$ Cf. H. Arendt. On Revolution. London: Penguin Books, 1990, p. 22. 
A pesar de una opinión bastante difundida, señala G. Marramao, no fue el legado francés en las negociaciones que llevaron al tratado de Westfalia, Longueville, quien lo habría utilizado por primera vez en $1646 .{ }^{12}$ Se trata de un término que ya existía en el lenguaje jurídico del Medioevo. De aquí pasó al lenguaje político, para referirse al proceso de expropiación de los bienes eclesiásticos, y, más tarde, al vocabulario del análisis histórico y cultural. En este ámbito ha circulado con dos significados opuestos. Por un lado, para expresar la ruptura entre el cristianismo y la modernidad (significado dominante en la cultura francesa, que sigue aquí el ideal emancipativo de la Revolución) y para expresar la continuidad-realización del cristianismo en la modernidad (significado dominante en la cultura alemana, que, a diferencia de la francesa, sigue aquí el modelo de la Reforma). ${ }^{13}$

Según Jean-Claude Monod, la historia de la secularización, como categoría de explicación histórica, comienza con Hegel. ${ }^{14}$ Ahora bien, como él mismo observa, quizás por las connotaciones políticas que había adquirido el término debido al uso napoleónico del mismo, Hegel nunca lo utiliza. En efecto, en su crítica de la religión, Hegel no habla de secularización, sino de Verweltlichung, de mundanización. Para uno de los más fervientes hegelianos, Karl Ludwig Michelet, señala Monod, el objetivo de toda la historia hegeliana es la mundanización del cristianismo. En el proyecto de Hegel, mundanizar el cristianismo consiste mantener el contenido de la religión, pero dándole una forma racional. Dios ya no estará separado de la naturaleza y de la historia, sino en ellas; extrañándose de sí mismo, haciéndose otro, en la primera, y realizándose, reconciliándose consigo mismo, en la segunda.

Monod también ha mostrado cómo el proceso de secularización iniciado por Hegel se prosigue a lo largo de toda la filosofía del siglo XIX, pero ya no como mundanización del contenido, sino de la forma racional y política que Hegel le había dado. Como éste, tampoco Nietzsche utiliza el término "secularización”, pero sí, “mundanización”. En la forma que Hegel le dio a su mundanización y en la modernidad en general, Nietzsche encuentra un cristianismo latente: de la fe en Dios se pasó a la fe en la mundanización, en la racionalidad del mundo y de la historia. Con Nietzsche el movimiento de la

\footnotetext{
${ }^{12}$ Cf. G. Marramao. Cielo y tierra. Genealogía de la secularización. Barcelona: Paidós, 1998, pp. 18-20.

${ }^{13}$ Cf. J-Cl. Monod. La querelle de la sécularisation. De Hegel à Blumenberg. Paris: Vrin, 2002, p. 29, especialmente la nota 1. Monod precisa que se trata de una esquematización. En efecto, Turgot, Quinet o Tocqueville, del lado francés, pondrán en cuestión la oposición entre modernidad y cristianismo. Del lado alemán, el joven Fichte se enrolará en los ideales de la emancipación.

${ }^{14}$ Cf. J-Cl. Monod. La querelle de la sécularisation. De Hegel à Blumenberg. Paris: Vrin, 2002, p. 45. Monod ha dividido la historia de la querella de la secularización en tres grandes etapas: la primera va de Hegel a Weber, la segunda está dedicada a la relación entre la secularización y la teología política (Carl Schmitt y Ernst Kantorowicz) y la tercera, a la discusión entre Karl Löwith y Hans Blumenberg sobre la legitimidad de la Modernidad.
} 
mundanización alcanza su forma paroxística, mundanizándose a sí mismo, es decir, denunciado la quimera $(W a b n)$ política de la mundanización.

4. Foucault retoma en varias oportunidades la respuesta de Kant a la cuestión planteada por la Berlinische Monatschrift, en 1784, como el punto de emergencia de la cuestión de la modernidad. ${ }^{15}$ Sin negar la necesidad de situar el texto kantiano en la tradición, incluso religiosa, del siglo XVIII, de la que sin duda forma parte; para Foucault, la respuesta de Kant rompe con la manera en la que la filosofía ha interrogado la actualidad. En efecto, el presente no aparece aquí como un momento de una determinada época del mundo (Platón), como anunciando necesariamente con sus signos a descifrar un acontecimiento futuro (San Agustín) o como el punto de transición hacia un nuevo mundo (Vico). ${ }^{16}$ En este sentido, la interpretación foucaultiana del texto de Kant se sitúa por afuera del horizonte interpretativo del concepto de secularización. Y, situándose afuera, hace de este mismo proceso una interpretación diferente al que hemos apenas descrito y que, más allá del período estudiado por Monod, continua ocupando un lugar de primer orden en la argumentación filosófica contemporánea. Basta pensar en las proyecciones más recientes de los análisis de Carl Schmitt, como, por ejemplo, las obras de Giorgio Agamben, Homo sacer (1995) y Il Regno e la Gloria (2007).

Para Foucault, más que el proceso de mundanización iniciado con Hegel y de mundanización de la mundanización, con Nietzsche; el la filosofía moderna hay que distinguir, más bien, dos grandes tradiciones: la analítica de la verdad, que estudia las condiciones del conocimiento verdadero, y la ontología del presente, que busca responder a la pregunta ¿qué es la actualidad? ${ }^{17}$

Este es, sin duda, uno de los mayores aportes de la lectura de Foucault. A nuestro modo de ver, es la noción de entusiasmo, como veremos, la que le permite llevar a cabo una lectura de la modernidad como actitud $y,{ }^{18}$ de este modo, situarse por afuera del horizonte interpretativo de la secularización, tanto en su versión hegeliana como nietzscheana. Por ello, Foucault deberá entrelazar la respuesta de Kant de 1784 con otro

\footnotetext{
${ }^{15}$ Se trata, según sus propias palabras, de un texto «fetiche» (cf. M. Foucault. Le Gouvernement de soi et des autres. Paris: Gallimard-Seuil, 2008, p. 8.), sobre el que podemos encontrar tres exposciones en sus escritos : 1) "What is Enlightenment?" publicado originariamente en P. Rabinow (ed.). The Foucault Reader. New York, 1984, pp. 32-50 y reimpreso en Dits et écrits. Vol. IV. Paris: Gallimard, 1994, pp. 562-578. 2) “Qu'est-ce que les Lumières?", aparecido originariamente en Magazine littéraire, $\mathrm{n}^{\circ}$ 207, mai. 1984, pp. 35-39 y reimpreso en Dits et écrits. Vol. IV, pp. 679-688. 3) Y la primera lección del curso de 1982-1983 en el Collège de France, publicado en M. Foucault. Le Gouvernement de soi et des autres. Paris: Gallimard-Seuil, 2008.

${ }^{16}$ Cf. M. Foucault. Dits et écrits. Vol. IV. Paris: Gallimard, 1994, pp. 563-564.

${ }_{17}$ Cf. M. Foucault. Le Gouvernement de soi et des autres. Paris: Gallimard-Seuil, 2008, pp. 21-22.

18 Foucault distingue, en efecto, entre la modernidad como época y como éthos, cf. M. Foucault. "Qu'est-ce que les Lumières?”, Dits et écrits. Vol. IV. Paris: Gallimard, 1994, p. 568.
} 
texto del filósofo de Königsberg, Der Streit der falkultäten, de 1798. Entre el primero y el segundo de estos textos se sitúan, precisamente, los acontecimientos de la Revolución francesa.

En el texto de 1784, como subraya Foucault, ${ }^{19}$ Kant nos da del iluminismo una definición finalmente negativa: el Iluminismo [Aufklärung] se define como la salida del hombre del estado de infancia o minoridad en el que se mantiene por su propia culpa. Este estado de minoridad, por pereza o comodidad, consiste en sustituir el entendimiento por un libro, que me dice lo que tengo que pensar, o la conciencia por un director, que me dice lo que tengo que hacer. En pocas palabras, se trata de poner la autoridad de otro en el lugar donde deberíamos hacer uso de nuestra propia razón. Consecuentemente, la divisa del Iluminismo será, "ten el coraje de servirte de tu propio entendimiento". ${ }^{20}$

Ahora bien, para Kant, la posibilidad de salir del estado de minoridad, más que en el esfuerzo individual, se encuentra en el uso público de la razón, es decir, en el uso de la razón que hace el sabio ante un público que lee. El uso privado de la razón, en cambio, es el que se tiene el derecho de hacer cuando se ocupa un determinado puesto civil o se desempeña una determinada función. ${ }^{21} \mathrm{El}$ uso privado de la razón tiene lugar cuando uno se sirve de la razón con objetivos que son distintos de ella; en el uso público, en cambio, el "räzonieren" está ordenado a sí mismo. Por ello, la distinción entre uso público y uso privado de la razón no debe ser confundida con la cuestión de la libertad de conciencia. ${ }^{22}$

Ahora bien, aunque la interpretación de Foucault tome en consideración la segunda parte, para comprender la significación y el alcance de la distinción entre uso público y privado de la razón, elemento fundamental de la lectura kantiana de su propia época; conviene tener presente la primera parte de Der Streit der Fakultäten. El tema general es la organización de la universidad, pero los argumentos esgrimidos van mucho más allá. Por un lado, Kant pone en juego aquí su entera concepción de la racionalidad y de la sociedad. En efecto, la polémica de la facultad de filosofía con las facultades superiores es, en definitiva, el cuestionamiento de la relación entre autoridad y razón que hasta entonces había determinado la concepción de la universidad y de las otras instituciones. No sorprende, por ello, que sea en este contexto que aparezca la noción de entusiasmo como categoría de interpretación histórica.

Según Kant, el origen de la universidad se encuentra en la idea de considerar industrialmente la totalidad del campo del saber, en aplicar el principio de la división del

\footnotetext{
${ }^{19}$ M. Foucault. “Qu'est-ce que les Lumières?”, Dits et écrits. Vol. IV. Paris: Gallimard, 1994, p. 564.

${ }^{20}$ I. Kant. Was ist Aufklärung?, AK VIII, p. 35.

${ }^{21}$ Cf. I. Kant. Was ist Aufklärung?, AK VIII, p. 37.

22 Cf. M. Foucault. Dits et écrits. Vol. IV. Paris: Gallimard, 1994, p. 566.
} 
trabajo de tal manera que existan profesores para cada sector científico. Lo que llamamos universidad no es más que el conjunto de los profesores que constituye una especie de república de sabios, una sociedad donde quienes deben obedecer las leyes son también los que las hacen. ${ }^{23}$ En esta república de sabios, los principales sectores del saber dan lugar a esas "pequeñas sociedades" que llamamos facultades y que se dividen en superiores e inferior. ${ }^{24}$ Esta denominación depende, siempre según Kant, del punto de vista del Estado. En efecto, son llamadas superiores aquellas facultades que interesan al Estado, que están directamente en relación con sus fines. Dado que, en vistas de sus fines, el Estado puede utilizar, como móviles para dirigir la conducta de sus súbditos, el bien eterno, el bien social y el bien corporal; las facultades superiores son: la de teología, la de derecho y la de medicina, mediante las cuales, respectivamente, el Estado puede ejercer una gran influencia sobre los pensamientos y decisiones íntimas de sus súbditos, controlar el comportamiento exterior de los súbditos a través de las riendas de las leyes públicas y asegurarse un pueblo fuerte y numeroso. Estas tres facultades superiores fundan sus enseñanzas en la escritura: la facultad de teología sobre la Biblia, la facultad de derecho sobre los códigos y la facultad de medicina sobre los reglamentos médicos. ${ }^{25}$

La facultad inferior es la facultad de filosofía, su función es garantizar la verdad, fin primero y esencial de la ciencia; lo que implica que está sometida sólo a la legislación de la razón, es decir, al poder de juzgar autónomamente. La facultad de filosofía, por su parte, se divide en dos departamentos, el de los conocimientos históricos (historia, geografía, filología), donde la enseñanza todavía se apoya en lo escrito, y el de conocimientos racionales puros (matemática, filosofía y metafísica puras), donde la enseñanza puede apoyarse sólo en la razón y no en la escritura.

Ahora bien, en tanto que a la facultad de filosofía le compete juzgar autónomamente, ella se opone a las facultades superiores como la verdad a la utilidad y a la autoridad. ${ }^{26} \mathrm{El}$ conflicto de las facultades es, por ello, un conflicto de racionalidades o, mejor, un conflicto entre los usos de la razón, entre un uso del conocimiento subordinado a los fines del Estado (teólogos, juristas y médicos son, en este sentido, funcionarios; profesionales, diríamos nosotros) y un uso autónomo de la razón.

\footnotetext{
23 “Ahora bien, en una universidad un tal departamento [el departamento de filosofía] debe ser fundado, esto es, debe haber una facultad de filosofía. En relación con las tres facultades superiores, sirve para controlarlas y series útil, puesto que todo depende de la verdad (la condición primera y esencial de la ciencia en general); la utilidad, al contrario, que las facultades superiores prometen para uso del gobierno, no es sino un momento de segundo rango." (I. Kant. Der Streit der Fakultäten, AK, VII, 28)

${ }^{24}$ Cf. I. Kant. Der Streit der Fakultäten, AK, VII, 17-18.

${ }^{25}$ Cf. I. Kant. Der Streit der Fakultäten, AK, VII, 23. En tanto que la medicina se ocupa de la física del cuerpo humano, pertenece a la facultad de filosofía, como el mismo Kant lo sugiere.

${ }^{26}$ Cf. I. Kant. Der Streit der Fakultäten, AK VII, pp. 27-28.
} 
A menos que la filosofía renuncie a si misma, a la búsqueda de la verdad, este conflicto es inevitable, y en él, la facultad inferior se opone, por un lado, a las facultades superiores y, por otro, al gobierno y también al pueblo. Se opone a las facultades superiores, porque todo el saber humano es competencia de la facultad de filosofía, no desde el punto de vista del contenido, sino en cuanto a la crítica, al juzgar los conocimientos desde el punto de vista de la verdad. Se opone al gobierno, porque éste no la puede censurar, excepto que obre contra sí mismo. Se opone al pueblo, porque éste no sitúa su dicha en la libertad, sino en los fines naturales: la felicidad después de la muerte, la garantía de su propiedad y el gozo físico de la vida. ${ }^{27}$

5. Ahora bien, volviendo al texto de 1784 , luego de haber definido en términos negativos al Iluminismo, como salida del estado de minoridad, y de haber establecido que el estado de adultez consiste en el uso público de la razón, con todo lo que ello implica en el orden de las relaciones entre los saberes y las instancias institucionales, Kant se pregunta si vivimos actualmente en una época iluminada.

A pesar de que los hombres no hayan todavía salido del estado de minoridad, Kant encuentra índices precisos que muestran que el camino ya está abierto. En el texto de 1784, este índice es la figura del príncipe Federico, "él tiene como deber no prescribir nada a los hombres en materia de religión, sino el concederles al respecto plena libertad". Desde este punto de vista, el siglo de las luces podría llamarse también "el siglo de Federico" ${ }^{28}$

Según Foucault, en el pensamiento kantiano y en el final del escrito de 1784 sobre todo, hay una excitación acerca de esta respuesta. En el texto de 1798, Der Streit der Fakultäten, esta vez en la segunda parte, Kant, en efecto, da una respuesta diferente, transfiriendo la función que atribuía a Federico II al entusiasmo por la Revolución. ${ }^{29}$ Esta respuesta, observa Foucault, no depende de una consideración teleológica de la historia. ${ }^{30}$ Para Kant, en efecto, la afirmación de que existe un progreso constante del género humano depende de la existencia de un signo que sea 1) rememorativum (que muestre que siempre ha sido asî), 2) demonstrativum (que también ahora es asî) y 3) pronosticum (que continuará siendo asî). ${ }^{31}$ La Revolución francesa es este signo; pero no la revolución en cuanto tal, sino el

\footnotetext{
27 I. Kant. Der Streit der Fakultäten, AK VII, p. 30.

${ }^{28}$ Cf. I. Kant. Was ist Aufklärung?, AK VIII, p. 40..

${ }^{29}$ Cf. M. Foucault. Le Gouvernement de soi et des autres. Paris: Gallimard-Seuil, 2008, p. 38. Sin abordar ahora los análisis de Jean-François Lyotard, no podemos, sin embargo, dejar de señalar que también éste ha puesto la noción de entusiasmo en el centro de la crítica kantiana de la historia. Su obra se titula, precisamente, L'Enthousiasme. Paris: Galilée, 1986.

${ }^{30}$ Cf. M. Foucault. Le Gouvernement de soi et des autres. Paris: Gallimard-Seuil, 2008, p. 17.

${ }^{31}$ Cf. I. Kant. Der Streit der Fakultäten, AK, VII, 84.
} 
entusiasmo como disposición de la humanidad que tiende a darse una constitución política conforme al derecho y que evite, al menos en principio, toda guerra ofensiva.

Juzgando la propia época a partir del entusiasmo que acompañó el acontecimiento revolucionario, según las expresiones de Foucault, Kant no establece una relación longitudinal con el presente, considerando como un momento de transición entre el pasado y el futuro; sino una relación sagital o vertical. ${ }^{32}$

$\mathrm{Si}$, como sostiene Foucault, la cuestión que emerge en estos escritos kantianos, como Was ist Aufklärung? y Der Streit der Fakultäten, y que define la ontología crítica del presente es “¿qué es este 'ahora' dentro del cual nos encontramos y que es el lugar, el punto desde el que escribo?"; ${ }^{33}$ la respuesta es, finalmente: el entusiasmo.

${ }^{32}$ Cf. M. Foucault. Le Gouvernement de soi et des autres. Paris: Gallimard-Seuil, 2008, p. 15.

${ }^{33}$ M. Foucault. Le Gouvernement de soi et des autres. Paris: Gallimard-Seuil, 2008, p. 13. 